\title{
Early Neonatal Outcome of Clinically Diagnosed Fetal Distress in Low Resource Areas
}

\author{
Arifa Akhter ${ }^{* 1}$, Asma Begum², Nadira Sultana ${ }^{3}$, Shampa Saha ${ }^{4}$, \\ Mubina Nuzhat Chowdhury ${ }^{5}$, ANM Saifullah ${ }^{6}$
}

\begin{abstract}
Introduction: Fetal distress is a high risk obstetric situation associated with increased perinatal morbidity and mortality. It is also a major contributor to operative interventions in the majority hospitals of developing countries. The objective of this study was to observe clinically diagnosed fetal distress and early neonatal outcome after delivery. Materials and Methods: This hospital based cross-sectional study was carried out in Department of Obstetrics and Gynecology at Bashundhara Addin Medical College Hospital, Keraniganj during the period of January to December 2019. 212 women in active phase of labor at term pregnancy who met the inclusion and exclusion criteria were enrolled. Fetal distress was diagnosed by abnormal FHR and lor presence of meconium in amniotic fluid after rupture of membrane. Neonatal outcome was assesss by 1st \& 5th mins Apgar Scores after delivery, babies requiring immediate resuscitation and admission to neonatal care unit \& recorded. Result: Among fetal distress $11.32 \%$ babies had Apgar score $<7$ as compared to babies without fetal distress that had $5.66 \%$ apgar score $<7$ at 5 th minutes $(p<0.05)$. 28.3\% fetal distressed born babies required NICU admission rather than only $9.44 \%$ of without fetal distress. Conclusion: This study shows relative adverse neonatal outcome for fetal distressed babies than without distress.
\end{abstract}

Keywords: Fetal distress, Apgar scores.

Number of Table: 04; Number of References: 20; Number of Correspondence: 06.

*1. Corresponding Author: Dr. Arifa Akhter

Assistant Professor

Department of Obstetrics \& Gynaecology

Bashundhara Addin Medical College Hospital, Keranigonj.

E mail: dr.arifa.ruma@gmail.com

Mobile 01609086668

2. Dr. Asma Begum

Registrar

Department of Obstetrics \& Gynaecology

Bashundhara Addin Medical College Hospital, Keranigonj.

3. Dr. Nadira Sultana

Assistant Professor

Department of Obstetrics \& Gynaecology

Bashundhara Addin Medical College Hospital, Keranigonj.

4. Dr. Shampa Saha

Junior Consultant

Department of Obstetrics \& Gynaecology

Bashundhara Addin Medical College Hospital, Keranigonj.

5. Dr. Mubina Nuzhat Chowdhury

Indoor Medical Officer

Department of Paediatrics

Dhaka Medical College Hospital, Dhaka.

6. Dr. ANM Saifullah

Assistant Professor

Department of Gastroenterology

Sir Salimullah Medical College \& Mitford Hospital, Dhaka.

\section{Introduction:}

Fetal distress is a widely used but poorly defined term ${ }^{1}$. Alternative terms- Nonreassuring fetal status (NRFS) which indicate that the fetus is compromised. It can be identified by suboptimal values in fetal heart rate, oxygenation of fetal blood \& other parameters ${ }^{2}$. Signs and symptoms of fetal distress include-decreased movement felt by mother (count to ten or Cardiff count to 10), meconium in the amniotic fluid, abnormal fetal heart rate (tachycardia $>180 \mathrm{bpm}$; bradycardia $<110 \mathrm{bpm}$, cardiotocography (persistent severe variable deceleration) and acid-base of capillary blood $\mathrm{PH}<7.15^{3,4}$. Some of these signs are more reliable predictors of fetal distress than others. For example; cardiotocography can give high false positive rates, even when interpreted by highly experienced medical personal. Acidosis is a highly reliable predictor, but is not always available. A highly effective method of assessment of distress would be to use fetal heart rate as a first indicator of distress ${ }^{2}$. In resource rich countries, the incidence of fetal distress is about $1 / 1000$ live births ${ }^{5}$. In resource-poor countries it is much more common i.e. 5-10/1000 live births ${ }^{6}$. The etiology of fetal distress may be present before the onset of labor (especially maternal disorder \& placental pathology) or occur during labor. About $23-40 \%$ of fetal distress occurred in pregnancies with no clinical risk factors ${ }^{7}$. Male fetuses are at increased risk for fetal distress during labor witch is evidenced by low Apgar scores or perinatal death ${ }^{8}$. The outcome of baby with fetal distress is quite variable. Severity can be ascertained by two clinical methods- (i) Apgar scores (ii) Measurement of degree of acidosis or hypoxia of fetal blood. Low Apgar scores were observed in neonates with moderate or severe fetal distress at delivery ${ }^{9}$. Severe fetal 
distress may results in cerebral oedema, seizures, necrotizing enterocolitis, epilepsy, mental retardation \& abnormal physical growth, perinatal death, or still birth but the majority will be normal ${ }^{10}$. To prevent severity of fetal distress, early diagnosis is to be made by close monitoring during labor and must be treated with intrauterine resuscitation technique including correction of maternal hypotension and /or the use of tocolytic agents ${ }^{11}$. Proper timing of delivery is also necessary. Fetal distress also affects the mode of delivery. Both instrumental as well as caesarean delivery has been found to be increased ${ }^{12}$. The main objective of this study was to observe early neonatal outcome of clinically diagnosed intrapartum fetal distress in terms of Apgar scores.

\section{Materials and Methods:}

This cross-sectional descriptive study was carried out from January 2019 to December 2019 in Obstetrics and Gynae Department at Bashundhara Addin Medical College Hospital, Keranigaoj. 212 women in active labor were enrolled for the study. Out of them 106 parturient with fetal distress were included in trial group (group-I) and 106 parturient having no fetal distress in comparison group(group-II). Inclusion criteria were women with ages between 18-35 years, singleton term pregnancy (37-40 weeks) with Cephalic presentation in active phase of labor. Multiple Pregnancy, pre-term labor, malpresentation, H/O lower segment caesarean section, cephalo-pelvic disproportion, pregnancy with medical disorders were excluded from this study. Informed consent was taken \& proper ethical clearance was obtained before study. Fetal distress was diagnosed by abnormal FHR and/or presence of meconium in amniotic fluid after rupture of membrane. Assessment of neonatal outcome was observed by, 1 st \& 5th minutes Apgar scores after delivery. Apgar score $<7$, babies requiring immediate resuscitation and admission to neonatal care unit were considered as adverse outcome of baby. The data was recorded in a predesigned questionnaires and analyzed by SPSS 22.0 software (SPSS, Inc. USA); for analysis chi-square test, Students T test were done where needed. $\mathrm{P}$ value $<0.05$ was assumed as significant.

\section{Results:}

Total 216 parturient were included in the study. During study period $16.4 \%$ parturient developed fetal distress.

Table -I shows the mode of delivery among the participants. Mode of delivery is significantly influenced by the fetal distress. There was raise of caesarean deliveries $(81.13 \%)$ in trial group.

Table-I: Mode of delivery among trial and comparison group

\begin{tabular}{lcccc}
\hline Mode of delivery & Case Group & $\%$ & Comparison group & $\%$ \\
\hline NVD & 20 & 18.87 & 88 & 83.02 \\
LUCS & 86 & 81.13 & 18 & 16.98 \\
Total & 106 & 100 & 106 & 100 \\
P value & $<0.0001$ & & & \\
\hline
\end{tabular}

Comparison between case and comparison group was significant. $(\mathrm{P}<0.0001)$. Only tachycardia \& thin meconium showed no association with low Apgar scores(Table-II).
Table-II: Clinical profile of fetal distress compared with Apgar score.

\begin{tabular}{lllcccc}
\hline Fetal distress & \multirow{2}{*}{} & $\%$ & \multicolumn{2}{c}{$\mathbf{A} / \mathbf{S}<7$ at 5 min } & \multicolumn{2}{c}{$\mathbf{A} / \mathbf{S}<7$ at 5 min } \\
\cline { 4 - 7 } & & & Number & Percentage & Number & Percentage \\
\hline Tachycardia & 11 & 10.37 & 0 & 0 & 11 & 9.43 \\
Bradycardia & 14 & 13.21 & 3 & 3.77 & 11 & 10.38 \\
Thick meconium & 40 & 37.73 & 2 & 1.89 & 38 & 35.84 \\
Thin meconium & 32 & 30.19 & 0 & 0 & 32 & 30.19 \\
Abnormal & 9 & 8.5 & & 5.66 & 03 & 2.84 \\
FHR+meconium & & & & & & \\
\hline Total & 106 & 100 & 12 & 11.32 & 94 & 88.68 \\
\hline
\end{tabular}

The distribution of early neonatal outcomes of two groups have shown in Table-III \& IV. In the present study $45.28 \%$ of trial group babies had low apgar score $(<7)$ at 1 st minute and $11.32 \%$ at 5 th minutes as compared to control group where $30.19 \%$ and $5.66 \%$ had Apgar scores $(<7)$ at 1 st minute 5 th minutes. A statistically significant difference $(\mathrm{p}<0.05)$ was observed in 1 st \& 5th min Apgar scores \& NICU admission. But there was no significant difference for perinatal mortality $(\mathrm{p}>0.05)$.

Table-III: Comparison of Apgar score between case \& comparison groups.

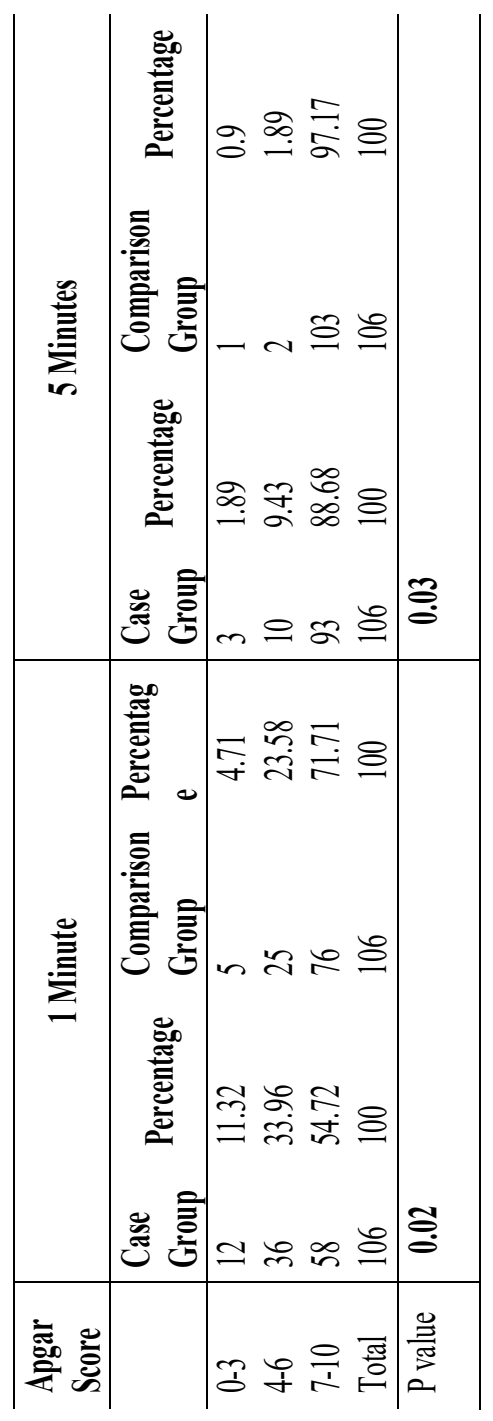


Table-IV: Distribution of early neonatal outcome between two groups.

\begin{tabular}{lccc}
\hline $\begin{array}{l}\text { Variable } \\
\text { outcomes }\end{array}$ & $\begin{array}{c}\text { Case Group } \\
\text { (\%) }\end{array}$ & $\begin{array}{c}\text { Comparison } \\
\text { Group (\%) }\end{array}$ & $\begin{array}{c}\text { P } \\
\text { value }\end{array}$ \\
\hline 1st min apgarscore $<7$ & $48(45.28 \%)$ & $30(30.19 \%)$ & 0.02 \\
5thminapgarscore $<7$ & $12(11.32 \%)$ & $3(5.66 \%)$ & 0.03 \\
Admission in NICU & $30(28.30 \%)$ & $10(9.43 \%)$ & 0.02 \\
Perinatal mortality & $2(1.89 \%)$ & $1(0.94 \%)$ & 0.2 \\
\hline
\end{tabular}

\section{Discussion:}

The incidence of fetal distress is found to be different in different studies ranging from $6.02 \%$ to $22 \%$. In the present study, the proportion is $16.5 \%$. S.S. Bhide, Ramachandra \& Gupta et al found the incidence is $6.02 \%, 9.6 \% \& 14.3 \%$ respectively ${ }^{13,14,15}$. Obstetricians feel unsafe about the state of the fetus, if there is abnormal FHR and the amnoitic fluid is meconium stained during labor even in places where other facilities of intrapartum monitoring like, fetal blood sampling and cardiotocography are available. This has influenced the mode of delivery. In present study, $81.13 \%$ of group I had caesarean delivery as compared to $16.98 \%$ in group II. Findings of this study is comparable to the studies done by Cliford et al who found caesarean section rate was 38\% in study group and $26 \%$ in control group ${ }^{16}$. In this study caesarean rate is too high as compared to other study, because instrumental delivery was not allowed by our patient. Ramachandra, Sashikala, Krzysztof et al also found increase rate of instrumental and caesarean delivery in fetal distress as compared to control group ${ }^{14,17,18}$. But Rossi et al did not find increased operative delivery ${ }^{19}$. Apgar scores have low predictive value for birth asphyxia as it is also affected by other factors. But in this study, we rely on the findings of apgar scores. In the present study $45.28 \%$ of distress born babies had low apgar score $(<7)$ at 1 st minute and $11.32 \%$ at 5 th minutes as compared to control group where $30.19 \%$ and $5.66 \%$ had Apgar scores $(<7)$ at 1 st \& 5th minutes respectively. These findings are comparable with different other studies. In the study of Ramachandra et al 13\% of meconium stained amniotic fluid (MSAF) babies were having low apgar score as compared to only $3.6 \%$ in clear liquor group at one minute. At 5 minutes this was $6 \%$ in MSAF born babies and $1.8 \%$ in clear liquor born babies ${ }^{14}$. Gupta et al showed $24.5 \%$ of distress babies had low apgar score at one minute compared to $4.1 \%$ in without distress born babies ${ }^{15}$. Ikechebelu JI found 36.5\% babies had Apgar scores of 7 and above, while $63.5 \%$ had Apgar scores $<7$ in fetal distress group ${ }^{20}$. In present study $28.3 \%$ babies were admitted to neonatal care unit among the babies born with distress group compared to only $9.44 \%$ of without distress babies, two babies $(1.89 \%)$ in study group had neonatal death (NND) both were born with thick meconium. Ikechebelu JI found 3.9\% perinatal mortality ${ }^{20}$.

\section{Conclusion:}

Clinically diagnosed Fetal Distress is accurate about one half of cases evidenced by low apgar scores which suggests a significant association with early neonatal outcome after delivery. So, immediate delivery is expedient in such cases. Future multicenter study is needed to support or refute the findings of the study.

Conflict of Interest: None.

Acknowledgement:

The authors would like to thank all participating patients for taking part in this study. Also thankful to all doctors, nursing staffs of labor ward \& dept. of neonatology who helped for making this study possible.

\section{References:}

1. Perer JT. What is fetal distress? AJOG. 1990; 162: 1421-1427.

https://doi.org/10.1016/0002-9378(90)90901-I

2. Fetal Distress". American Pregnancy Association. August 2015. Retrieved March 1, 2018.

3. Chalmers I. Randomized,controlledtrails of intrapartum fetal monitoring. In: Thalhammer O, Baumgarten K \&Pollak A. (eds) Perinatal medicine. 6th European Congress. Vienna. 1981: 260-265.

4. Beischer NA, Mackay EV, Colditz PB.: Obstetrics \& the Newborn. 3rd ed. W.B Saunders Company Ltd. 24-28 Oval Road London Nw 17DX. 1997; 493-499.

5. Thornberg E. Thiringer K. Odeback A, Milsom I. Birth asphyxia: incidence, clinical course \& outcome in swedish population ActaPaediatr. 1995; 84: 927-932 (Pubmed).

https://doi.org/10.1111/j.1651-2227.1995.tb13794.x

PMid:7488819

6. Jones G, Steketee RW, Black RE, Bhutta ZA, Morris SS. Bellagio Child Survival Study Group. How many child deaths can we prevent this year? Lancet. 2003 Jul 5;362(9377):65-71.

https://doi.org/10.1016/S0140-6736(03)13811-1

7. Low JA, Simson LL, Tomi G, Chambeelain S. Limitation in the clinical prediction of intrapartum fetal asphyxia. Amjobstet Gynecol. 1995; 172: 801-4.

https://doi.org/10.1016/0002-9378(95)90002-0

8. TNO Foundation for perinatal Epidemiology, AJOG 2002; 187(6): 1605-1607.

9. Borruto F, Comparetto C, Freisser A: Prevention of Cerebral Palsy during Labour: Role of fetal lactate. Arch Obst\&Gynaecol. 2008 July; 278(1): 17-22.

https://doi.org/10.1007/s00404-007-0531-1

PMid:18071726

10. Perlman JM, Tack ED, Martin T, Shackelford G, Amon E. Acute Systemic Organ Injury in Term Infants After Asphyxia. Am J Dis Child. 1989;143(5):617-620.

https://doi.org/10.1097/00132582-198910000-00022 
https://doi.org/10.1001/archpedi.1989.02150170119037

PMid:2718998

11. J Gynecol Obstet Biol Report (Paris). 2008 Feb, 37; suppl, 1: s46-55, 1819340 (P,S,G,E,B,D).

12. Oladapo OT, Sotimehin SA, Ayoola-Sotubo O. Predictors of Severe Neonatal [13] Compromise Following Caesarean Section for Clinically Diagnosed Foetal Distress. WAJM. 2009;28(5):327-32.

https://doi.org/10.4314/wajm.v28i5.55014

PMid:20383839

13. Bhide S.S, Shendurnikar N, Aiyer S and Baxi S. R Neonatal outcome after meconium stained amniotic fluid. Journal of Obstetrics and Gynaecology of India. 1993; 933-935.

14. Ramachandra V, Horrela M. Significance of meconium staining of amniotic fluid. Journal perinatology Medicine. 1990; 18 (5): 345-349.

https://doi.org/10.1515/jpme.1990.18.5.345

PMid:2292757

15. Gupta V, Bhatia BD, Mishra OP. Meconium stained amniotic fluid: antenatal, intrapartum and neonatal attributes. Indian Pediatr. 1996 Apr;33(4):293-7.
16. Clifford J. Bochner, Arnold L. Medearis, Michael G. Ross, Gary K. Oakes. The role of ante partum testing in the management of term pregnancies with heavy meconium in early labor. Obstetrics and Gynaecology. 1987 June; 69 (6): 903-907.

17. Shashikala A, Raghavan S, Mishra N, Khatoons. Perinatal outcome in relation to mode of delivery in meconium stained amniotic fluid. Indian J. Pediatrics. 1995; 2: 63-67.

https://doi.org/10.1007/BF02752185

PMid:10829845

18. Krzyszof-J Urbaniak, Lesely M.E. McCowan, Kevin M Townedn. Risk factors for meconium-aspiration syndrome. Aus NZ J ObstetGynae. 1996; 36(4):401-406.

https://doi.org/10.1111/j.1479-828X.1996.tb02180.x

PMid:9006821

19. Elena M Rossi, Elliot H. Philipson, Thomas G. Williams. Meconium Aspiration Syndrome: Intrapartum and Neonatal Attributes. American Journal of Obstetrics and Gynaecology.1989; 161:1106-10.

https://doi.org/10.1016/0002-9378(89)90643-1

20. Ikechebelu JI. Accuracy of clinical diagnosis of foetal distress. J Coll Med. 2004; 9:12-13. 